\title{
Effect of oxygen on multidrug resistance in the first trimester human placenta
}

\author{
P. Lye, E. Bloise, C. Dunk, M. Javam, W. Gibb, S.J. Lye, S.G. \\ Matthews
}

Version Post-print/Accepted Manuscript

Citation Lye, P., E. Bloise, C. Dunk, M. Javam, W. Gibb, S. J. Lye, and S. G.

(published version) Matthews. "Effect of oxygen on multidrug resistance in the first trimester human placenta." Placenta 34, no. 9 (2013): 817-823.

doi: 10.1016/i.placenta.2013.05.010

Copyright/License

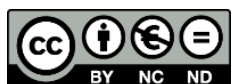

This work is licensed under the Creative Commons

Attribution-NonCommercial-NoDerivatives 4.0

International License. To view a copy of this license, visit http://creativecommons.org/licenses/by-nc-nd/4.0/.

How to cite TSpace items

Always cite the published version, so the author(s) will receive recognition through services that track citation counts, e.g. Scopus. If you need to cite the page number of the author manuscript from TSpace because you cannot access the published version, then cite the TSpace version in addition to the published version using the permanent URI (handle) found on the record page.

This article was made openly accessible by $U$ of $T$ Faculty. Please tell us how this access benefits you. Your story matters. 
Elsevier Editorial System(tm) for Placenta

Manuscript Draft

Manuscript Number: PL-13-20004R1

Title: EFFECT OF OXYGEN ON MULTIDRUG RESISTANCE IN THE FIRST TRIMESTER HUMAN PLACENTA

Article Type: Original Article

Keywords: P-glycoprotein, BCRP, first trimester placenta, hypoxia, hyperoxia, multidrug resistance, $\mathrm{ABC}$ transporters

Corresponding Author: Dr. Enrrico Bloise, D.V.M., M.Sc., Ph.D.

Corresponding Author's Institution: Department of Physiology, University of Toronto, ON, Canada

First Author: Phetcharawan Lye, B.Sc., M.Sc.

Order of Authors: Phetcharawan Lye, B.Sc., M.Sc.; Enrrico Bloise, D.V.M., M.Sc., Ph.D.; Caroline Dunk, Ph.D.; Mohsen Javam, B.Sc.; William Gibb, Ph.D.; Stephen J Lye, Ph.D.; Stephen G Matthews, Ph.D.

Abstract: Introduction: The multidrug resistance proteins, P-glycoprotein (P-gp, encoded by the ABCB1 gene) and breast cancer resistance protein (BCRP, encoded by ABCG2) are highly expressed in the first trimester placenta. These transporters protect the fetus from exposure to maternally derived toxins and xenobiotics. Since oxygen is a regulator of multidrug resistance in various tissues, we hypothesized that changes in oxygen tension alter placental ABCB1/P-gp and ABCG2/BCRP expression in the first trimester.

Methods: Placental specimens were collected from first $(n=7)$, second $(n=5)$ and term pregnancies $(\mathrm{n}=5)$. First trimester placental villous explants were incubated $(24$ or $48 \mathrm{~h})$ in different oxygen tension (3-20\%). ABCB1, ABCG2 and VEGFA mRNA expression levels were assessed by RT-PCR and protein was localized by IHC.

Results: ABCB1 is expressed most highly in the first trimester placenta $(\mathrm{p}<0.05)$, whereas ABCG2 expression does not change significantly over pregnancy. P-gp and BCRP staining is present in the syncytiotrophoblast and in cytotrophoblasts. ABCG2 mRNA is increased in hyperoxic $(20 \%)$ conditions after $48 \mathrm{~h}(\mathrm{p}<0.05)$. In contrast, hypoxia $(3 \%)$ did not change ABCB1 mRNA expression but significantly increased VEGFA mRNA ( $\mathrm{p}<0.05)$. Hypoxia resulted in increased BCRP staining in cytotrophoblasts and in the microvillous membrane of the syncytium. Whereas, hypoxia resulted in increased P-gp staining in proliferating cytotrophoblasts.

Conclusion: We conclude that placental multidrug resistance expression, specifically ABCG2, is regulated by oxygen tension in the first trimester. It is possible that changes in placental oxygen supply are capable of altering fetal drug exposure especially during early pregnancy. 


\section{Response to Reviewers}

\section{Manuscript No:PL-13-20004-R1}

\section{Response to Reviewers}

We are grateful to the reviewers for their thoughtful consideration of our manuscript. We have addressed all of the reviewers' comments in this fully revised version of the manuscript. We believe the new version of the manuscript is clearer and more focused.

We have addressed each of the specific comments of the reviewers below:

1. As noted in the paper, perfusion of the intervillous space occurs between 8-10 weeks. Considering this statement, the oxygen tension to which villi had been exposed from the 1st trimester specimens harvested may have varied substantially, as 7, 8, and 9-week specimens were described in the 1st trimester group. Please evaluate the data for specimens from each week and state there was, or was not, a uniform mRNA and IHC staining for all specimens examined, independent of week of 1 st trimester collection.

R: We thank the reviewer for this important comment. We therefore grouped qPCR and IHC staining results by weeks of gestation. For qPCR results, placental explants were obtained at 7-8wk $(\mathrm{n}=5)$ and 8.1$9 \mathrm{wk}(\mathrm{n}=2)$. The majority of explants were in the earlier group, and we did not have sufficient numbers in the later group to allow statistical comparison between gestational weeks. However, visual assessment of the data did not reveal consistent differences between the two groups. For IHC results, placental explants were obtained at $8 \mathrm{wk}(\mathrm{n}=1)$ and 9.1-9.6 $\mathrm{wk}(\mathrm{n}=5)$. The majority of explants were in the later group and we did not observe any consistent differences in staining intensity between the later and earlier group. We added this new information in the manuscript, please see lines: 147-150 and 169-171.

2. How was the viability of the explants confirmed over the time of culture?

R: First trimester trophoblast viability was assessed by measuring LDH (L-lactate dehydrogenase) levels in the supernatant of explants cultured in different oxygen tension (3 - 20\%) over time (24 and $48 \mathrm{hs).} \mathrm{A}$ two-way ANOVA followed by Bonferonni's test was then performed. The two-way ANOVA showed a time of culture effect for LDH release; LDH was higher at $24 \mathrm{~h}$ compared to $48 \mathrm{~h}(\mathrm{p}<0.05)$. This would suggest that viability of $1^{\text {st }}$ trimester explants improved over time of culture (from 24 to $48 \mathrm{~h}$ of culture). Importantly, there was no significant effect of oxygen tension on $\mathrm{LDH}$, indicating that culture of $1^{\text {st }}$ trimester trophoblast in different oxygen tension (3-20\%) for up to $48 \mathrm{~h}$ does not change explant viability. We incorporated this information in the manuscript as follows:

- $\quad$ Materials \& Methods, lines 61-64 and 110

- Results, lines 151 and 161-164.

- Figure legends: we added a new figure, Fig3H,

- We added a new reference [18]

3. The authors should describe the histology of the villi in the explants over time in culture, compared to tissues obtained at placental harvest, time zero. This (hopefully) will verify the absence of a change in histology (esp. loss of syncytium) during culture. Additionally, examination of cytospins of the medium after the 24 and $48 \mathrm{~h}$ incubations should be done to verify that loss of syncytium, cytotrophoblasts, or both from the explants during incubation did not affect the mRNA analyses.

R: As the reviewer suggested we have added the histological analyses of first trimester explants at time zero (placental harvest), and following 24 and $48 \mathrm{~h}$ of culture. We observed that in comparison to the T0 control, explants cultured for $24 \mathrm{~h}$ showed an increase in the cytotrophoblast cell number, more rounded nuclei and a thinning of the trophoblast bilayer at all oxygen tensions. At $20 \% \mathrm{O}_{2}$, there was the 
appearance of small vacuoles in the syncytiotrophoblast membrane. By $48 \mathrm{~h}$ of culture, explants at $3 \% \mathrm{O}_{2}$ showed an increase in cytotrophoblast proliferation with multiple layers of trophoblast visible in a thickened trophoblast bilayer. Explants at $8 \% \mathrm{O}_{2}$ appeared to be stable and resemble $\mathrm{T} 0$ controls in cytotrophoblast cell number and distribution of the nuclei in the syncytiotrophoblast. Explants at $20 \% \mathrm{O}_{2}$ show syncytial necrosis and detachment.

We added this information in the Results section (lines 152-164); Discussion section (lines 244-248); Figure 3 Legends and added new images to Figure 3.

We agree with the reviewer that would be interesting to determine cytospins of the medium after the 24 and $48 \mathrm{~h}$ incubations. However, the fact that we obtained consistent values for the A260/A280 ratio and good quality electropherogram peaks of the total RNA extracted from all groups analyzed, together with the histological analysis that does not show any loss of syncytium or cytotrophoblast, indicates that we were comparing similar cell populations in each placental explant.

4. Were observers examining the IHC specimens blinded to antibody-antigen source when evaluating the slides? How were the "representative images" selected?

R: Observers were not blinded to the antibody, however they were blinded to gestational age and explant oxygen tension. After analysis of the whole slide per sample, the site that reflected the most representative image of the whole sample was captured and displayed as "Representative image" of that particular group. This information was included in the manuscript as follows: Lines 101-102 and 104105.

5. Statements on lines 123-124 suggest a quantified analysis was done of the IHC. i.e. ".as P-gp levels in the syncytium decreased with advancing gestation. In first trimester, BCRP levels were low in the cytotrophoblast and syncytium, however, levels increased substantially towards term (Fig 1F-H)." Please describe in Methods how the analysis of the IHC specimens were scored for staining: e.g. cell type with expression, sub-cellular location (e.g. microvillous membrane, cytoplasmic, "apical membrane"), and intensity?

R: Immunostaining intensity for P-gp and BCRP was evaluated by two different observers blinded to gestational age and oxygen tension. Since differences in staining intensity were visually evident among different gestational time points or in different oxygen tension, we did not use any additional scoring system to evaluate these differences; due to the fact that such scoring systems are as equally semiquantitative in nature. In order to make it clearer, we have modified the text lines as follows: Lines 123129. Additionally, each cell type (syncytiotrophoblast, cytotrophoblast) was analyzed individually and cellular immunostaining was simultaneously compared to other samples, lines 128-129.

6.The same concern is raised about the quantified statements for the IHC in lines 153-155: "P-gp immunostaining appeared to be increased in proliferating cytotrophoblasts in the hypoxic first trimester placenta. In contrast, in hyperoxia there was cytotrophoblast necrosis and loss of polarity of P-gp staining (Fig 4). Hypoxia resulted in a substantial increase in BCRP expression in cytotrophoblasts and the microvillous membrane of the syncytium. ".

R: Please see response to point 5. Accordingly, we have made changes in the manuscript. See lines 166171.

7. What does "apical" mean in the statement: "levels at the apical membrane of the cytotrophoblasts" 
R: We named the apical membrane of the cytotrophoblasts the membrane which is in direct contact with the syncytiotrophoblast. To avoid confusion, we have removed the term "apical" from the manuscript and re-phrased the description of our results more clearly. See lines 123-125 and 190-194.

8. Lines 137-138: "While there was a trend for increased ABCB1 mRNA levels in hypoxic villous explants at both time points, these effects did not reach statistical significance (Fig. 2A). " The data show NO difference based on the authors definition of significance. If a "trend" is real, the authors should obtain more data to prove or disprove significance. Line 163 in the discussion should also be changed as well as in the abstract as the statements are not the best description of the data: i.e. "There was a trend for increased placental ABCB1 mRNA and ."

R: We have removed our reference to 'trends' throughout the manuscript. Please see abstract and lines 140-141 and 178-180.

9. Did the result reported on line 147 really occur within $48 \mathrm{~h}$ ? "Histological analysis in first trimester villous explants cultured in different oxygen tension (3-20\%) was undertaken, in order to monitor syncytial shedding and regeneration in the culture system (Fig 3)." If syncytial shedding did indeed occur within this time frame, then the concern raised above in item \#2 is a major issue.

R: Please see response to point 3.

10. Although the authors measured pO2's appropriately, villous explants are likely all hypoxic at the trophoblast medium interface, as $15-30 \mathrm{mg}$ clusters would limit oxygen exchange across the medium of the intervillous space, in the absence of stirring medium.

R: We agree that it is possible that impaired oxygen exchange may occur in the absence of stirring medium. However, the fact VEGFA mRNA expression was up-regulated only in the $3 \% \mathrm{O}_{2}$ regimen, indicate that established hypoxia pathways were activated under these conditions. Importantly, if there was an important limitation of oxygen exchange due to explant size in the 8 and $20 \% \mathrm{O}_{2}$ groups, we would anticipate activation of VEGFA; this did not occur (Fig 2C). The fact that VEGFA mRNA is overexpressed only in the $3 \% \mathrm{O}_{2}$ regimen validates our culture system and current results.

11. Lines 173-176 state: "We identified a similar distribution and gestational changes in the syncytiotrophoblast, however, due to higher resolution with the D11 antibody we also discovered, high levels of P-gp in the apical membrane of the cytotrophoblast adjacent to the basolateral membrane of the syncytiotrophoblast. " Please clarify how one obtains "higher resolution" from the use of a different antibody using a method that depends on the optics of the microscope and the presence of an enzyme reaction product deposition from peroxidase. Again, clarify what "apical surface" of cytotrophoblasts describes line (176).

R: These sentences have been modified accordingly. Please see lines: 187-194.

12. As the placenta develops in a $\mathrm{pO} 2<20 \mathrm{~mm} \mathrm{Hg}$, the authors should comment on how their findings of changes in ABCG2 expression relates in vivo where the "normal" implantation environment is hypoxic?

$\mathrm{R}$ : This important point is updated accordingly in lines 205-215; 227-232.

Reviewer \#2: 
The authors conclude that placental multidrug resistance expression, specifically ABCG2, is regulated by oxygen tension in the first trimester, and possible that changes in placental oxygen supply are capable of altering fetal drug exposure especially during early pregnancy. It is a nice observation, however the role of hypoxia and oxygenation and reperfusion that occurs with the opening of the spiral arteries at 9-10 $\mathrm{w}$ is not enough discussed, and the role of OFR and a possible effect on ABCG2,is not mentioned.

$\mathrm{R}$ : We thank for the reviewer for their suggestions and have included additional discussion in the revised manuscript. Please see lines 216-227.

In addition, the authors should provide more information on the collection of early pregnancy placentas.

R: Normal first trimester placental tissue is collected by the Research Centre for Women's and Infants' Health (RCWIH) BioBank program staff and is delivered to us within 2 hours in $1 \%$ PBS without $\mathrm{Ca}^{2+}$ or $\mathrm{Mg}^{2+}$. Apart from gestational age, no other information is provided to us apart (as per guidelines determined by the Mount Sinai Hospital and University of Toronto Research Ethics Boards). We added further information in the manuscript. Please see line 53. 


\section{ATTN: Placenta Editorial Board}

Original Article Submission

We would like for our original research article, titled "Effect of Oxygen on Multidrug Resistance in the First Trimester Human Placenta" to be considered for publication in Placenta. We feel that this article is well-suited for publication in Placenta, as it presents novel findings that have considerable implications for fetal protection and development. This article provides new information on how changes in placental oxygen tension can potentially impair fetal protection against harmful factors present in the maternal circulation. Previous studies have shown that oxygen is a potent regulator of multidrug resistance proteins in different tissues, including cancer cells. However, it is not known whether oxygen regulates placental multidrug resistance. In the present study, we show that the multidrug resistance protein, $A B C G 2 / \mathrm{BCRP}$ expression is modulated by oxygen. These novel findings have considerable implications for pregnant women taking prescription medication, or where pathologies result in altered placental oxygenation. We believe that this article will be of greatest interest to scientists and medical professionals who are specialized in the fields of pharmacology, obstetrics, gynecology, and pediatrics, among others. The authors of this manuscript are Phetcharawan Lye, Enrrico Bloise, Caroline Dunk, Mohsen Javam, William Gibb, Steve J. Lye and Stephen G. Matthews. We included an additional author, M Javam, who performed additional experiments included in the present version. This manuscript represents original, unpublished material not under editorial consideration elsewhere. These studies were undertaken following all appropriate institutional guidelines. We do not have any professional or financial conflicts of interest.

Thanking you in advance for your consideration.

With kind regards,

Corresponding Author:

Enrrico Bloise,

Postdoctoral Fellow, Department of Physiology, Faculty of Medicine, Medical Sciences Building, Rm 3302, University of Toronto, 1 King's College Circle, Toronto, ON Canada, M5S 1A. 

PLACENTA

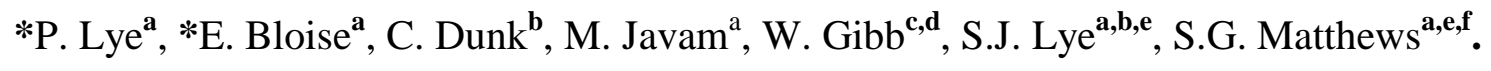

${ }^{\text {a }}$ Department of Physiology, University of Toronto, Toronto, Canada

b Samuel Lunenfeld Research Institute, Mount Sinai Hospital, Toronto, Canada

${ }^{\mathbf{c}}$ Departments of Obstetrics \& Gynecology, University of Ottawa, Ottawa, Canada

${ }^{\mathbf{d}}$ Departments of Cellular \& Molecular Medicine, University of Ottawa, Ottawa, Canada

${ }^{\mathbf{e}}$ Department Obstetrics \& Gynecology, University of Toronto, Toronto, Canada

${ }^{\mathbf{f}}$ Department of Medicine, Faculty of Medicine, University of Toronto, Toronto, Ontario, Canada.

*P. Lye and E. Bloise share joint first-authorship.

Short Tile: Placental multidrug resistance and oxygen tension

Keywords: P-glycoprotein, BCRP, first-trimester placenta, hypoxia, hyperoxia, multidrug resistance

Grant Support: This study was funded by the Canadian Institutes for Health Research (grant: FRN-57746; to S.G.M. and W.G.).

Disclosure Summary: Authors have nothing to declare

Correspondence and reprint requests:

Dr. Enrrico Bloise,, Department of Physiology, Faculty of Medicine, Medical Sciences Building, Rm 3302, University of Toronto, 1 King's College Circle, Toronto, ON Canada, M5S 1A.

Tel: (416) 978-1974 Fax:(416) 978-4940 e-mail: enrrico.bloise@ utoronto.ca 


\section{ABSTRACT}

2 Introduction: The multidrug resistance proteins, $\mathrm{P}$-glycoprotein (P-gp, encoded by the $A B C B 1$ gene) and 3 breast cancer resistance protein (BCRP, encoded by $A B C G 2$ ) are highly expressed in the first trimester 4 placenta. These transporters protect the fetus from exposure to maternally derived toxins and xenobiotics. 5 Since oxygen is a regulator of multidrug resistance in various tissues, we hypothesized that changes in 6 oxygen tension alter placental $A B C B 1 / \mathrm{P}$-gp and $A B C G 2 / \mathrm{BCRP}$ expression in the first trimester.

7 Methods: Placental specimens were collected from first $(n=7)$, second $(n=5)$ and term pregnancies $(n=5)$. 8 First trimester placental villous explants were incubated (24 or $48 \mathrm{~h})$ in different oxygen tension (3-20\%). $9 A B C B 1, A B C G 2$ and $V E G F A$ mRNA expression levels were assessed by RT-PCR and protein was 10 localized by IHC.

11 Results: $A B C B 1$ is expressed most highly in the first trimester placenta ( $<<0.05)$, whereas $A B C G 2$ 12 expression does not change significantly over pregnancy. P-gp and BCRP staining is present in the 13 syncytiotrophoblast and in cytotrophoblasts. ABCG2 mRNA is increased in hyperoxic (20\%) conditions 14 after $48 \mathrm{~h}(\mathrm{p}<0.05)$. In contrast, hypoxia (3\%) did not change $A B C B 1$ mRNA expression but significantly 15 increased VEGFA mRNA (p<0.05). Hypoxia resulted in increased BCRP staining in cytotrophoblasts and 16 in the microvillous membrane of the syncytium. Whereas, hypoxia resulted in increased P-gp staining in 17 proliferating cytotrophoblasts.

18 Conclusion: We conclude that placental multidrug resistance expression, specifically $A B C G 2$, is 19 regulated by oxygen tension in the first trimester. It is possible that changes in placental oxygen supply 20 are capable of altering fetal drug exposure especially during early pregnancy. 
1

4

\section{Introduction}

Fetal protection against harmful factors present in the maternal blood is critical for normal fetal growth and development across gestation. Fetal exposure to xenobiotics during early stages of pregnancy can disrupt normal organogenesis and elicit teratogenic effects [1]. In this context, the multidrug resistance proteins, P-glycoprotein (P-gp; encoded by the $A B C B 1$ gene) and breast cancer resistance protein (BCRP; encoded by the $A B C G 2$ gene) play a crucial role in fetal protection [2]. They are abundantly expressed in the human placenta and efflux substrates present in the syncytiotrophoblast back towards the maternal compartment, preventing substrate accumulation in the fetus [2]. $A B C B 1 / \mathrm{P}-\mathrm{gp}$ is highly expressed at the level of mRNA and protein in the first $\left(1^{\text {st }}\right)$ trimester placenta but decrease progressively with advancing gestation [3]. Placental $A B C G 2$ mRNA does not change as gestation progresses, whereas BCRP protein levels increase towards term [4]. This indicates that P-gp and BCRP expression are differentially regulated across gestation and likely play time-dependent specific roles in syncytiotrophoblast biology and fetal protection.

During blastocyst implantation into the maternal decidua, extravillous trophoblast cells (EVTs) invade and remodel maternal spiral arteries. This process promotes dilation of the maternal spiral arterioles, which increases blood flow into the intervillous space, providing nutrient and oxygen supply for the growing placenta and developing embryo [5,6]. At around 10-12 weeks of gestation, the placenta becomes haemochorial [7] and until this time, the uterine glands provide histiotrophic nutrition for the fetus [8]. Consequently, there is no direct contact between placental inter-villous spaces and maternal erythrocytes until the haemochorial placenta is formed [9]. Thus, $1^{\text {st }}$ trimester trophoblast tissues are exposed to low oxygen tension and hence hypoxic conditions. During this critical period, impaired maternal artery invasion and or remodeling, can lead to adverse conditions such as local hypoxia, hyperoxia, hypoxia-reoxygenation and mechanical injury, which have the potential to cause deleterious outcomes such as intrauterine growth restriction (IUGR), preeclampsia, unexplained miscarriage, preterm labour and placental abruption $[5,6,9.10]$. 
The correlation between hypoxia and multidrug resistance proteins has been previously demonstrated

27 in different cancer types and hematopoietic cells. Cancer and hematopoietic stem cells thrive in low 28 oxygen conditions [11,12] and both $A B C B 1 / \mathrm{P}$-gp and $A B C G 2 / \mathrm{BCRP}$ are highly expressed [11,13]. In 29 addition, hypoxia is known to induce $A B C B 1 / \mathrm{P}-\mathrm{gp}$ expression and activity through activation of hypoxia30 inducible factors (e.g. Hif-1 $\alpha$ and Hif-2 $\alpha$ ) [14]. However, the effect of hypoxia may be cell-type specific 31 as $A B C B 1$ expression was not affected in a human glioma cell line maintained under hypoxic conditions 32 [15]. With respect to $A B C G 2$ and BCRP, Hif- $1 \alpha$ and Hif-2 $\alpha$ activation increase expression in cardiac 33 cells, and promote survival in normal cells exposed to hypoxic conditions $[11,16,17]$. Moreover, Hif- $1 \alpha$ 34 has been shown to bind to hypoxia responsive elements in the $A B C B 1$ and $A B C G 2$ promoters [11,14]. 35 Together, this suggests that changes in oxygen tension might potently modulate placental multidrug 36 resistance expression. This would impact fetal exposure to toxins and xenobiotics in the maternal 37 circulation. In the present study, we hypothesized that oxygen regulates placental multidrug resistance in 38 the $1^{\text {st }}$ trimester trophoblast and therefore, we conducted experiments to evaluate whether variations in 39 oxygen tension are capable of altering multidrug resistance expression in the $1^{\text {st }}$ trimester trophoblast.

\section{Materials and Methods}

\subsection{Placental tissue collection}

All placental specimens were obtained from the Research Centre for Women's and Infants' Health (RCWIH) BioBank program of the Mount Sinai Hospital, in accordance with the policies of the Mount Sinai Hospital and University of Toronto Research Ethics Boards. Placental tissue specimens were collected from informed consented healthy $1^{\text {st }}(7-9$ weeks' gestation; $n=7)$ and second $\left(2^{\text {nd }}\right)$ trimester $(16$ -

4718 weeks' gestation; $\mathrm{n}=5$ ) pregnancies and from normal term controls ( $>37$ weeks' gestation, caesarian 48 delivery $n=5)$. 
52 Human placental tissue specimens were processed within $2 \mathrm{~h}$ of collection. On collection, specimens were 53 placed into $1 \%$ PBS without $\mathrm{Ca}^{2+}$ or $\mathrm{Mg}^{2+}$. In the laboratory, explants were further dissected into villous 54 clusters of about $15-30 \mathrm{mg}$. Villous explants were then cultured in 24 well plates in preconditioned (at $558 \% \mathrm{O}_{2}$ for $24 \mathrm{~h}$ ) DMEM/F12, containing antibiotic (Normocin;Invivogen,), and supplemented with 1xITS56 A (insulin, transferrin and selenium-A; Invitrogen, Carlsbad, California, USA) for $24 \mathrm{~h}$ in $8 \% \mathrm{O}_{2}$ tension. 57 On the following day, villous explants were randomly divided and placed at $3 \% \mathrm{O}_{2}-5 \% \mathrm{CO}_{2}$ $58\left(\mathrm{pO}_{2} \sim 22.8 \mathrm{mmHg}\right), 8 \% \mathrm{O}_{2}-5 \% \mathrm{CO}_{2}(\mathrm{pO} 2 \sim 60.8 \mathrm{mmHg})$ or $20 \% \mathrm{O}_{2}-5 \% \mathrm{CO}_{2}\left(\mathrm{pO}_{2} \sim 152 \mathrm{mmHg}\right)$ for either $24 \mathrm{~h}$ 59 or $48 \mathrm{~h}$. Villous explants ( $\mathrm{n}=7$ for each time point and oxygen tension) were collected at $24 \mathrm{~h}$ and $48 \mathrm{~h}$. 60 Explants were flash frozen and stored at $-80^{\circ} \mathrm{C}$ for total RNA extraction or were fixed in $4 \%$ PFA for 61 histology and immunohistochemistry. Conditioned media was collected from tissue explants for

Total RNA was extracted from explants using RNeasy@ Plus Universal Mini Kit (QIAGEN,

67 Toronto, ON, Canada) according to the manufacturer's instructions. RNA concentration and purity were 68 measured using the NanoDrop 1000 Spectrophotometer (Wilmington, DE, USA) and the Experion RNA 69 StdSens Analysis Kit (Bio Rad, Mississauga, ON, Canada) respectively. RNA was reverse-transcribed to 70 cDNA using the iScript Reverse Transcription Supermix (Bio Rad) according to the manufactor's 71 instructions and stored at $-80^{\circ} \mathrm{C}$.

72 Levels of $A B C B 1$ (P-gp), $A B C G 2$ (BRCP) and VEGFA (Vascular endothelial growth factor A) mRNA 73 were examined by real time RT-PCR, using SYBR ${ }^{\circledR}$ Green qPCR ReadyMix ${ }^{\mathrm{TM}}$ (Sigma-Aldrich, St. 74 Louis, MO, USA) and the CFX 380 Real-Time system C 1000 TM Thermal Cycle (Bio Rad) with the 75 following cycling conditions: initial enzyme $95^{\circ} \mathrm{C}$ for 5 min followed by 38 cycles of $95^{\circ} \mathrm{C}$ for $15 \mathrm{sec}$ and $60^{\circ} \mathrm{C}$ for $20 \mathrm{sec}$. Different housekeeping genes were assessed for stability of expression under the 
different oxygen tensions [19]. The housekeeping genes tested were: zeta polypeptide (YWHAZ), TATAbinding protein $(T B P)$, hypoxanthine-guanine phosphoribosyltransferase $(H P R T)$, glyceraldehyde 3phosphate dehydrogenase (GAPDH), DNA topoisomerase 1 (TOP1) and beta-2-microglobulin $(B 2 M)$. As a result, expression levels following explant exposure to different oxygen tensions were normalized to the geometric mean of the two most stable housekeeping genes: YWHAZ and TBP. Data was analyzed using CFX Manager Software (Bio Rad). Primer sequences for the genes analyzed are listed in Table 1. Levels of placental $A B C B 1$ and $A B C G 2$ mRNA expression in the $1^{\text {st }}, 2^{\text {nd }}$ and third $\left(3^{\text {rd }}\right)$ trimesters (developmental analysis) were normalized to the geometric mean of the housekeeping genes $Y W H A Z$, HPRT and succinate-ubiquinone oxidoreductase (SDHA) [19].

\subsection{Histology and immunohistochemistry}

Fresh placental tissue and villous explants were fixed overnight in $4 \%$ PFA, embedded in paraffin, sectioned $(5 \mu \mathrm{m})$ and processed as previously described [3]. Briefly, paraffin sections were mounted on microscope slides, dewaxed in xylene and rehydrated in ethanol in descending gradients. Hematoxylin and eosin (H\&E) staining was performed to determine the morphology of the tissue sections. For immunohistochemistry endogenous peroxidase activity was quenched during the rehydration step with $3 \%$ (vol/vol) hydrogen peroxide solution in absolute methanol (Sigma-Aldrich) for $30 \mathrm{~min}$ at room temperature. Following a PBS wash antigen retrieval was performed by adding $5 \mathrm{ug} / \mathrm{ml}$ of proteinase $\mathrm{K}$ (Roche, Mississauga, ON, Canada) at $37^{\circ} \mathrm{C}$ for $10 \mathrm{~min}$. Sections were again washed in PBS before blocking in protein blocking solution (Dako, Burloak, ON, Canada) for 1 hour. Slides were incubated overnight with the primary antibodies: anti-mouse MDR-1 (1:500, D-11, Santa Cruz) and anti-mouse BCRP (1:200, BXP-21, Santa Cruz Biotechnology, Dallas, TX, USA). Mouse IgG1 was added instead of primary antibody in non-immune controls. Slides were washed in PBS, incubated with secondary antibody (1:300, 1h, room temperature; goat anti-mouse, Dako). Sections were washed in PBS and incubated (1h) with streptavidin-HRP (Dako); staining was detected with the peroxidase substrate kit DAB (Dako). Slides were counterstained with hematoxylin, dehydrated in ethanol and coverslipped. The site that reflected the most representative image of each sample was captured using an Olympus BX61 
upright, motorized microscope with an Olympus DP72 digital colour camera run by CellSens Standard 104 proprietary acquisition software (Olympus Canada, Markham, Ontario, Canada). Observers were blinded 105 to gestational age $\left(1^{\text {st }}, 2^{\text {nd }}\right.$ and $3^{\text {rd }}$ trimester specimens $)$ and explant treatment group.

\subsection{Statistical analysis}

Values for all data are expressed as means +/- SEM and were analyzed using Prism (GraphPad considered if $p<0.05$.

\section{Results}

\subsection{Developmental expression and localization of $\mathrm{ABCB} 1 / P$-gp and $\mathrm{ABCG} 2 / B C R P$ with advancing} gestation.

Previously, we have demonstrated that $A B C B 1 / \mathrm{P}-\mathrm{gp}$ expression decreased progressively with advancing gestation [3], whereas placental BCRP protein levels increased towards term with no change in $A B C G 2$ mRNA expression [4]. In order to confirm and extend our previous findings, we investigated the expression and localization pattern of placental multidrug resistance in a well-characterized sample set across gestation. $A B C B 1$ mRNA was highly expressed in $1^{\text {st }}$ trimester trophoblast specimens $(p<0.05)$; levels then decreased with advancing gestation. In contrast, levels of $A B C G 2$ mRNA remained unchanged across pregnancy (Fig 1A). Visual assessment of P-gp signal (D-11 antibody) identified stronger P-gp staining at the syncytium-facing membrane of the cytotrophoblast, at the microvillus membrane of the syncytium as well as in the cytoplasm of the syncytium in $1^{\text {st }}$ trimester (Fig 1B, C, D). P-gp staining in the syncytium became weaker with advancing gestation. In $1^{\text {st }}$ trimester, BCRP staining was less evident in the cytotrophoblast and syncytium, however immunostaining became substantially stronger towards 
term (Fig 1F-H). Syncytiotrophoblast and cytotrophoblast cells were individually visually assessed and

sequentially compared across samples.

\subsection{Housekeeping gene expression in villous explants cultured in different oxygen tension.}

A number of housekeeping genes were evaluated in order to identify a set of genes that would maintain stable expression levels $48 \mathrm{~h}$ after exposure to a range of different oxygen tension (3-20\%; Table 2). The most stable genes were $Y W H A Z$ and $T B P$. TOPI expression variation was similar to $T B P$ whereas, HPRT, GAPDH, and B2M demonstrated a high variation among different oxygen tensions. $Y W H A Z$ and $T B P$ were subsequently used to normalize all the mRNA expression of our genes of interest.

\subsection{Effects of oxygen on ABCB1 and ABCG2 expression.}

Villous explants were exposed to different oxygen tension (3\%,8\% and 20\%) for either $24 \mathrm{~h}$ or $48 \mathrm{~h}$. Two-way ANOVA analysis revealed an effect of duration of exposure $(p<0.05)$ for $A B C B 1$ mRNA expression, such that there was an increase in $A B C B 1$ expression with time in culture at all oxygen tensions. However, $A B C B 1 \mathrm{mRNA}$ levels in hypoxic (3\%) villous explants were not different from the 8 or $20 \%$ explants at either time point (Fig. 2A). An effect of time in culture and oxygen tension exposure was also evident for $A B C G 2$ mRNA levels $(p<0.05)$. Further, hyperoxia increased $A B C G 2$ mRNA levels $(p<0.01)$ after $48 \mathrm{~h}$ exposure to $20 \% \mathrm{O}_{2}$ (Fig. $\left.2 \mathrm{~B}\right)$, when compared to hypoxic villous explants $\left(3 \% \mathrm{O}_{2}\right)$. In order to assess whether hypoxic pathways were being activated in our culture system, VEGFA mRNA expression was evaluated [20-22]. An oxygen tension exposure effect was observed for VEGFA mRNA expression $(p<0.05)$ demonstrating that $V E G F$ mRNA expression was higher in villous explants exposed to $3 \% \mathrm{O}_{2}$ compared to hyperoxic conditions (Fig. 2C). mRNA levels of reference genes, multidrug resistance genes and VEGFA did not appear to be different between placental explants obtained at 7-8wk $(n=5)$ and 8.1-9 wk $(n=2)$. The majority of explants were in the earlier group, and we did not have sufficient numbers in the later group to allow statistical comparison.

\subsection{Histological structure and cell viability of $1^{\text {st }}$ trimester human placenta}


occurring in the explant culture system, histological analysis was undertaken at time zero (placental

harvest Fig 3A) and following 24h (Fig 3B-D) and 48h of culture (Fig 3E-G). After 24h, visual inspection

revealed an increase in cytotrophoblast cell number, more rounded nuclei and a thinning of the trophoblast bilayer at all oxygen tensions in comparison to the $\mathrm{T} 0$ control. At $20 \% \mathrm{O}_{2}$ there was appearance of small vacuoles in the syncytiotrophoblast membrane. After $48 \mathrm{~h}$ of culture, explants at $3 \%$

$\mathrm{O}_{2}$ showed an increase in cytotrophoblast proliferation with multiple layers of trophoblast visible in a thickened trophoblast bilayer. Explants at $8 \% \mathrm{O}_{2}$ appeared to be stable and resemble $\mathrm{T} 0$ controls in cytotrophoblast cell number and distribution of the nuclei in the syncytiotrophoblast suggesting adaption to the culture system. Explants at $20 \% \mathrm{O}_{2}$ show the initiation of syncytial necrosis and detachment. This adaption of the explants to the time in culture was also demonstrated by the significant decrease in LDH levels at $48 \mathrm{~h}$ of culture as compared to $24 \mathrm{~h}(\mathrm{p}<0.05)$. No statistical effects were found between the different oxygen tensions at either time point (Fig 3H).

\section{Effects of oxygen on multidrug resistance immunolocalization in $1^{\text {st }}$ trimester placenta.}

P-gp immunostaining appeared to be stronger in proliferating cytotrophoblasts in the hypoxic $1^{\text {st }}$ trimester placenta. In contrast, there was cytotrophoblast necrosis and loss of polarity of P-gp staining in hyperoxic conditions (Fig 4). Hypoxia resulted in a stronger BCRP staining in cytotrophoblasts and the microvillus membrane of the syncytium. The week of gestation (i.e. stage of pregnancy; 8 -10ws) did not appear to impact the oxygen-mediated changes in P-gp and BCRP staining intensity and distribution in the cultured explants.

\section{Discussion}

Early placental development occurs under hypoxic conditions $[5,6,9,10]$ and the multidrug resistance proteins, $A B C B 1 / \mathrm{P}$-gp and $A B C G 2 / \mathrm{BCRP}$ are highly expressed in the $1^{\text {st }}$ trimester placenta $[2,3,4]$. We 176 found that $A B C G 2$ mRNA was induced by hyperoxic (20\%) conditions after $48 \mathrm{~h}$. In contrast, BCRP 
signal was stronger under hypoxic conditions, indicating a disconnect between $A B C G 2$ expression and

BCRP protein expression. $A B C B 1 \mathrm{mRNA}$ expression remained unaltered in different oxygen tensions, whereas P-gp staining was stronger in the membranes of the cytotrophoblast/syncytium of villous explants exposed to hypoxic conditions (3\%).

The fact that placental $A B C B 1 / \mathrm{P}$-gp expression is high in the $1^{\text {st }}$ trimester compared to the $2^{\text {nd }}$ and $3^{\text {rd }}$ trimesters $[2,3]$ suggests that oxygen may represent an important factor regulating its expression. Using a well-characterized set of placental samples derived at different stages of gestation, we found high levels of $A B C B 1 \mathrm{mRNA}$ in $1^{\text {st }}$ trimester, but low levels at term. In contrast, $A B C G 2 \mathrm{mRNA}$ levels were high throughout pregnancy and did not change with advancing gestation. These findings were consistent with previous studies by our group and others [3,4,23-26], indicating that $A B C B 1 \mathrm{mRNA}$ levels are high during periods of hypoxia. In a previous study, using the P-gp (G-1) antibody, we localized P-gp signal to the syncytiotrophoblast and demonstrated increased staining in $1^{\text {st }}$ trimester than at term [3]. Accordingly in the present study, using the P-gp (D11) antibody, we identified a similar distribution and gestational changes in the syncytiotrophoblast. Additionally, due to a higher definition of D11 signal, we were able to clearly differentiate the cytotrophoblasts from the syncytium. Which allowed us to identify the presence of P-gp staining in the syncytium-facing membrane of the cytotrophoblast, adjacent to the basolateral membrane of the syncytiotrophoblast. Identification of $\mathrm{P}$-gp on the syncytium-facing membrane of the cytotrophoblast suggests that P-gp may not only play a very important role in fetal protection (i.e. in the syncytiotrophoblast), but may also play a novel role in cytotrophoblast function such as substrate delivery to the syncytium. Future studies are required to investigate the role of P-gp in cytotrophoblast proliferation, cell survival and fusion.

In contrast to $\mathrm{P}$-gp, BCRP protein levels in the syncytium increase at term with no change $A B C G 2$ mRNA. This indicates a substantial disconnect between gene expression and translation to protein. The $1^{\text {st }}$ trimester placenta has relatively low oxygen levels, with a $\mathrm{pO}_{2}$ of around $20 \mathrm{mmHg}(2.8 \mathrm{kPa})$ [9]. However, in later stages of human pregnancy, due to increased oxygen demands of the developing fetus, placenta $\mathrm{pO}_{2}$ levels increase to around $60 \mathrm{mmHg}(8 \mathrm{kPa})$ [9]. This suggests, at least at the level of protein, 
that increasing placental oxygen levels [9] might represent an important factor regulating placental BCRP protein levels with advancing pregnancy.

In $1^{\text {st }}$ trimester villous explants, hyperoxia (20\% oxygen) for $48 \mathrm{~h}$ resulted in a significant increase in $A B C G 2$ mRNA expression compared to expression in explants maintained under hypoxic conditions.

This finding is somewhat counterintuitive, given that $A B C G 2$ mRNA levels do not change significantly between $1^{\text {st }}$ and $3^{\text {rd }}$ trimester when placental oxygen levels are known to increase substantially. While it is unlikely that $\mathrm{PO}_{2}$ tensions will increase to $20 \%$ in the $1^{\text {st }}$ trimester in vivo, future studies are required to determine at which point increasing $\mathrm{O}_{2}$ tensions positively regulate $A B C G 2$. In this regard, it is possible that more gradual increases in oxygen tension as occur with advancing pregnancy are not capable of modifying $A B C G 2$ mRNA expression, whereas rapid changes in oxygen tension, as simulated in the present model, are capable of inducing $A B C G 2$ mRNA expression. It is also possible that other regulatory factors modulate $A B C G 2 \mathrm{mRNA}$ and that these override any modulatory effect of oxygen with advancing gestation.

During early pregnancy, oxygen tension rises progressively within the intervillous space from $\sim 20$ $\mathrm{mmHg}(2.5 \%)$ at 8 weeks to $60 \mathrm{mmHg}(8.5 \%)$ at 12 weeks [27]. This substantial rise in blood flow is due to endovascular extravillous trophoblast invasion into the uterine spiral arterioles. This process results in remodeling of the spiral arteries [5,6,9], which enables increased maternal blood to flow into the early placenta [27]. Early deficiencies in spiral artery remodeling have the potential to elicit placental hypoxia and oxidative stress. $[5,6,9,10,27]$. In contrast a sudden increase in early utero-placental blood flow is also associated with increased hyperoxidative stress, a major cause of early pregnancy loss [27]. Interestingly, multidrug resistance proteins have been suggested to play a role in extruding toxic products of oxidative stress that have been produced during an insult or to compensate for the loss of efflux pumps in damaged tissues, ameliorating oxidative stress and preventing further tissue damage [28]. It is possible that in such cases, alterations in BCRP expression due to impaired oxygenation or increased oxidative stress alter placental BCRP substrate clearance and therefore delivery to the fetus. Moreover, transient changes in placental oxygen levels such as when the placenta switches from a low to higher $\mathrm{O}_{2}$ environment, also 
have the potential to change BCRP expression and therefore, fetal drug exposure. However, in the present study, we identified a substantial increase in BCRP with hypoxia as assessed by immunohistochemistry. This indicates, as observed for developmental changes, that there is significant disconnect between regulation of $A B C G 2$ mRNA level and BCRP protein. This clearly requires further investigation.

In contrast to the situation for $A B C G 2$ mRNA, there was a trend for increased $A B C B 1$ mRNA expression when villous explants were cultured in more hypoxic conditions over time. However, this trend did not reach significance. While not quantitative, immunohistochemical analysis of the hypoxic explants revealed an apparent increase in P-gp levels in the cytotrophoblast and syncytium compared to hyperoxic conditions. The fact that $A B C B 1 \mathrm{mRNA}$ is highly expressed in the $1^{\text {st }}$ trimester placenta when $\mathrm{O}_{2}$ levels are low, together with the present data suggest that more hypoxic conditions may induce $A B C B 1$ mRNA and P-gp expression. This could potentially lead to increased protection of the fetus from the influence of toxins and xenobiotics in the maternal circulation during hypoxia

In the present study, we carefully characterized whether villous explants developed other hypoxiarelated changes. As predicted [20-22] VEGFA mRNA was significantly elevated in the $3 \% \mathrm{O}_{2}$ group demonstrating that hypoxic pathways were activated in our culture system at both time points. Moreover, we also identified hyperproliferation of the cytotrophoblast under hypoxia and a resultant thickening of the syncytium. At more physiological $\mathrm{O}_{2}$ levels $(8 \%)$ explants appear to adapt with time to the culture system and resemble freshly dissected placenta. In contrast, under hyperoxic conditions there was vacuolization and associated damage to the syncytiotrophoblast by $48 \mathrm{~h}$ of culture although we did not observe an increase in LDH release from these tissues.

Together, these findings suggest that oxygen regulates placental multidrug resistance across pregnancy and that changes in optimal placental oxygen supply during pregnancy may have important implications for fetal drug exposure. Importantly, inadequate trophoblast invasion and failed vascular remodeling of the uterine spiral arteries in the $1^{\text {st }}$ trimester can lead to compromised placental perfusion and result in chronic placental ischemia and hypoxia later in gestation [27,29]. Such conditions can lead to pre-eclampsia and IUGR, or even preterm delivery [29-31]. Further well-characterized experiments are 
warranted to evaluate whether placental multidrug expression and function are altered in these placental

256 pathologies. Our findings also highlight the need to carefully control the oxygen environment when

257 performing in vitro experiments to investigate the expression and function of placental multidrug 258 resistance.

\section{Conclusions}

In summary, we have demonstrated, for the first time, that oxygen can regulate the expression of

261 placental multidrug resistance genes in the $1^{\text {st }}$ trimester. It is of critical importance to understand 262 placental multidrug resistance across pregnancy, in order to prevent fetal exposure to toxins and 263 xenobiotics present in the maternal circulation. These factors, depending on the time and length of 264 exposure, can have deleterious effects for the embryo/fetus and impact pregnancy outcome.

\section{References}

267 [1] Gilbert-Barness E. Teratogenic causes of malformations. Ann Clin Lab Sci 2010; 40(2):99-114.

268 [2] Iqbal M, Audette MC, Petropoulos S, Gibb W, Matthews SG. Placental drug transporters and their 269 role in fetal protection. Placenta 2012;33(3):137-42.

270 [3] Sun M, Kingdom J, Baczyk D, Lye SJ, Matthews SG, Gibb W. Expression of the multidrug resistance 271 P-glycoprotein, (ABCB1 glycoprotein) in the human placenta decreases with advancing gestation. 272 Placenta 2006;27(6-7):602-9.

273 [4] Yeboah D, Sun M, Kingdom J, Baczyk D, Lye SJ, Matthews SG, Gibb W. Expression of breast 274 cancer resistance protein $(\mathrm{BCRP} / \mathrm{ABCG} 2)$ in human placenta throughout gestation and at term before and 275 after labor. Can J Physiol Pharmacol 2006;84(12):1251-8.

276 [5] Patel J, Landers K, Mortimer RH, Richard K. Regulation of hypoxia inducible factors (HIF) in 277 hypoxia and normoxia during placental development. Placenta 2010;31(11):951-7. 
[6] Tuuli MG, Longtine MS, Nelson DM. Review: Oxygen and trophoblast biology--a source of 279 controversy. Placenta 2011;32 Suppl 2:S109-18.

[7] Foidart JM, Hustin J, Dubois M, Schaaps JP. The human placenta becomes haemochorial at the 13th 281 week of pregnancy. Int J Dev Biol 1992;36(3):451-3.

[9] Murray AJ. Oxygen delivery and fetal-placental growth: Beyond a question of supply and demand? Placenta 2012;33 Suppl 2:e16-22.

[10] Burton GJ, Jauniaux E. Placental oxidative stress: from miscarriage to preeclampsia. J Soc Gynecol Investig 2004;11(6):342-52

[11] Krishnamurthy P, Ross DD, Nakanishi T, Bailey-Dell K, Zhou S, Mercer KE, Sarkadi B, Sorrentino BP, Schuetz JD. The stem cell marker Bcrp/ABCG2 enhances hypoxic cell survival through interactions with heme. J Biol Chem 2004;279(23):24218-25.

294 [13] Callaghan R, Crowley E, Potter S, Kerr ID. P-glycoprotein: so many ways to turn it on. J Clin 295 Pharmacol 2008;48(3):365-78.

296 [14] Comerford KM, Wallace TJ, Karhausen J, Louis NA, Montalto MC, Colgan SP. Hypoxia-inducible 297 factor-1-dependent regulation of the multidrug resistance (MDR1) gene. Cancer Res 2002;62(12):338729894.

299 [15] Liang BC. Effects of hypoxia on drug resistance phenotype and genotype in human glioma cell lines $300 \quad$ J Neurooncol 1996;29(2):149-55. 
[16] Martin CM, Ferdous A, Gallardo T, Humphries C, Sadek H, Caprioli A, Garcia JA, Szweda LI, 302 Garry MG, Garry DJ. Hypoxia-inducible factor-2alpha transactivates Abcg2 and promotes cytoprotection 303 in cardiac side population cells. Circ Res 2008;102(9):1075-81.

304 [17] Natarajan K, Xie Y, Baer MR, Ross DD. Role of breast cancer resistance protein (BCRP/ABCG2) in 305 cancer drug resistance. Biochem Pharmacol 2012;83(8):1084-103.

318 [22] Wang K, Jiang YZ, Chen DB, Zheng J. Hypoxia enhances FGF2- and VEGF-stimulated human 319 placental artery endothelial cell proliferation: roles of MEK1/2/ERK1/2 and PI3K/AKT1 pathways. $320 \quad$ Placenta 2009;30(12):1045-51.

321 [23] Mylona P, Hoyland JA, Sibley CP. Sites of mRNA expression of the cystic fibrosis (CF) and 322 multidrug resistance (MDR1) genes in the human placenta of early pregnancy: No evidence for 323 complementary expression. Placenta 1999;20(5-6):493-6. 
324 [24] Gil S, Saura R, Forestier F, Farinotti R. P-glycoprotein expression of the human placenta during 325 pregnancy. Placenta 2005;26(2-3):268-70.

326 [25] Mathias AA, Hitti J, Unadkat JD. P-glycoprotein and breast cancer resistance protein expression in 327 human placentae of various gestational ages. Am J Physiol Regul Integr Comp Physiol 2005;289(4):9633289.

329 [26] Staud F, Cerveny L, Ceckova M. Pharmacotherapy in pregnancy; effect of ABC and SLC 330 transporters on drug transport across the placenta and fetal drug exposure. J Drug Target 2012;20(9):73633163.

332 [27] Pringle KG, Kind KL, Sferruzzi-Perri AN, Thompson JG, Roberts CT. Beyond oxygen: complex 333 regulation and activity of hypoxia inducible factors in pregnancy. Hum Reprod Update 2010;16(4):41533431.

335 [28] Huls M, Russel FG, Masereeuw R. The role of ATP binding cassette transporters in tissue defense 336 and organ regeneration. J Pharmacol Exp Ther 2009;328(1):3-9.

337 [29] Chaddha V, Viero S, Huppertz B, Kingdom J. Developmental biology of the placenta and the origins 338 of placental insufficiency. Semin Fetal Neonatal Med 2004;9(5):357-69.

339 [30] Burton GJ, Woods AW, Jauniaux E, Kingdom JC. Rheological and physiological consequences of 340 conversion of the maternal spiral arteries for uteroplacental blood flow during human pregnancy. Placenta $3412009 ; 30(6): 473-82$.

342 [31] Viero S, Chaddha V, Alkazaleh F, Simchen MJ, Malik A, Kelly E, Windrim R, Kingdom JC. 343 Prognostic value of placental ultrasound in pregnancies complicated by absent end-diastolic flow velocity 344 in the umbilical arteries. Placenta 2004;25(8-9):735-41. 


\section{Figure Legend}

\section{Figure Legends}

Figure 1: Developmental expression and localization of $A B C B 1 / P$-gp and $A B C G 2 / B C R P$ with advancing gestation. (A): mRNA expression of the multidrug resistance genes $(A B C B 1$ and $A B C G 2)$ in $1^{\text {st }}(\mathrm{n}=7), 2^{\text {nd }}$ $(\mathrm{n}=5)$ and $3^{\text {rd }}$ (Term-Cesarean Section, $\mathrm{n}=5$ ) trimester placentas. One-way ANOVA followed by the Newman-Keuls post-hoc test. * represents significant differences among $1^{\text {st }}, 2^{\text {nd }}$ and TermCS placental specimens. ( $p<0.05)$. (B-I) Representative images of placental P-gp (B-D) and BCRP (F-H) immunostaining of 7-9, 16-18 and >37 (Term C-section) weeks of gestation (n=2/group). (E,I) nonimmune mouse IgG1 controls. CT cytotrophoblasts; ST syncytiotrophoblasts. 9

Figure 2: Effects of oxygen on $A B C B 1$ and $A B C G 2$ expression. $A B C B 1(\mathrm{~A}), A B C G 2$ (B) and VEGFA (C) mRNA expression ( $\mathrm{n}=7 / \mathrm{group})$ in $1^{\text {st }}$ trimester villous explants $(7-9 \mathrm{wk})$ cultured in different oxygen tension (3,8 and 20\% $\mathrm{O}_{2}$ ). Two-way ANOVA followed by Bonferroni's post test. * represents differences between 20 and $3 \% \mathrm{O}_{2}$ for $A B C G 2$ and $V E G F A$ at the $48 \mathrm{~h}$ time point. Whereas, * represents differences among 3, 8 and $20 \% \mathrm{O}_{2}$ for $V E G F A$ at the $24 \mathrm{~h}$ time point. ( $p<0.05$ ). Lines represent differences between time 24 and $48 \mathrm{hs}$.

Figure 3: Histological analysis of first trimester human placenta exposed to different oxygen tensions. Representative images of freshly dissected villous explants (A) and explants cultured for 24 (B-C) and 48h (D-G) at 3\% (B and E), 8\% (C and F) and 20\% (D and G) $\mathrm{O}_{2}$ tensions followed by $\mathrm{H} \& \mathrm{E}$ staining $(\mathrm{n}=3$ /group). Arrow indicates proliferating cytotrophoblasts in the 3\% 48h explant. (H) Two-way ANOVA showed a time dependent decrease in the release of LDH between 24 and $48 \mathrm{~h}$ of culture $(p<0.05)$. Lines represent differences between time 24 and $48 \mathrm{hs}$.

Figure 4: Multidrug resistance immunolocalization in first trimester trophoblast exposed to different oxygen tension. Representative images of placental P-gp (A-C) and BCRP (D-F) immunostaining of 8-10 weeks of gestation cultured in 3\% (A,D), $8 \%$ (B,E) and 20\% (E,F). (n=6/group;). Arrow indicates fetal Hoeffbauer cells; CT, cytotrophoblasts; ST, syncytiotrophoblast. 
Click here to download Table: Table .docx

Table 1: Primers used for real-time PCR

\begin{tabular}{clc}
\hline Gene symbol & \multicolumn{1}{c}{ Sequence } & References \\
\hline \multirow{2}{*}{$A B C B 1$} & $\begin{array}{l}\text { Forward: AGC AGA GGC CGC TGT TCG TT } \\
\text { Reverse: CCA TTC CGA CCT CGC GCT CC }\end{array}$ & $*$ \\
\hline \multirow{2}{*}{$A B C G 2$} & $\begin{array}{l}\text { Forward: TGG AAT CCA GAA CAG AGC TGG GGT } \\
\text { Reverse: AGA GTT CCA CGG CTG AAA CAC TGC }\end{array}$ & $*$ \\
\hline \multirow{2}{*}{ EEGF } & $\begin{array}{l}\text { Forward: CGG GCC TCC GAAA CCA TGA ACT T } \\
\text { Reverse: CCC TCC TCC TTC TGC CAT GGG T }\end{array}$ & $*$ \\
\hline \multirow{2}{*}{ FAPDH } & $\begin{array}{l}\text { Forward: GGC TAT CCA GCG TAC TCC AAA } \\
\text { Reverse: CGG CAG GCA TAC TCA TCT TTT T }\end{array}$ & {$\left[\begin{array}{l}\text { Forward: AGA TCA TCA GCA ATG CCT CC } \\
\text { Reverse: CAT GAG TCC TCC CAC GAT AC }\end{array}\right.$} \\
\hline \multirow{2}{*}{$H P R T$} & $\begin{array}{l}\text { Forward: TGA CAC TGG CAA AAC AAT GCA } \\
\text { Reverse: GGT CCT TTT CAC CAG CAA GCT }\end{array}$ & {$[18]$} \\
\hline \multirow{2}{*}{ SDHA } & $\begin{array}{l}\text { Forward: TGG GAA CAA GAG GGC ATC TG } \\
\text { Reverse: CCA CCA CTG CAT CAA ATT CAT G }\end{array}$ & {$[18]$} \\
\hline \multirow{2}{*}{$T O P 1$} & $\begin{array}{l}\text { Forward: TGC ACA GGA GCC AAG AGT GAA } \\
\text { Reverse: CAC ATC ACA GCT CCC CAC CA }\end{array}$ & {$\left[\begin{array}{l}\text { Forward: GAT GAA CCT GAA GAT GAT GGC } \\
\text { Reverse: TCA GCA TCA TCC TCA TCT CG }\end{array}\right.$} \\
\hline \multirow{2}{*}{ YWHAZ } & $\begin{array}{l}\text { Forward: ACT TTT GGT ACA TTG TGG CTT CAA } \\
\text { Reverse: CCG CCA GGA CAA ACC AGT AT }\end{array}$ & {$[18]$} \\
\hline
\end{tabular}

* Gene specific primers were designed using Primer-BLAST (http://www.ncbi.nlm. nih.gov/tools/primerblast/).

Table 2: Coefficient of variance of the housekeeping genes of $1^{\text {st }}$ trimester trophoblast explants exposed to different oxygen tension for $48 \mathrm{~h}$.

\begin{tabular}{ccccc}
\hline Gene symbol & $\begin{array}{c}48 \mathrm{~h} / \mathbf{3 \%} \mathbf{O}_{\mathbf{2}} \\
\text { means } \pm \mathrm{SEM} \\
\mathrm{n}=4\end{array}$ & $\begin{array}{c}48 \mathrm{~h} / \mathbf{8 \%} \mathbf{O}_{\mathbf{2}} \\
\text { means } \pm \mathrm{SEM} \\
\mathrm{n}=4\end{array}$ & $\begin{array}{c}48 \mathrm{~h} / \mathbf{2 0 \%} \mathbf{O}_{\mathbf{2}} \\
\text { means } \pm \text { SEM } \\
\mathrm{n}=4\end{array}$ & $\begin{array}{c}\text { Coefficient of } \\
\text { variance }(\%)\end{array}$ \\
\hline$Y W H A Z$ & $22.66 \pm 0.31$ & $22.22 \pm 0.31$ & $22.70 \pm 0.42$ & 3.1 \\
$T B P$ & $28.59 \pm 0.40$ & $28.19 \pm 0,35$ & $28.52 \pm 0,70$ & 3.4 \\
$T O P 1$ & $24.14 \pm 0.34$ & $23.82 \pm 0.33$ & $23.92 \pm 0.67$ & 3.5 \\
$H P R T$ & $27.48 \pm 0.43$ & $26.98 \pm 0.49$ & $27.21 \pm 0.98$ & 4.4 \\
$G A P D H$ & $20.32 \pm 0.54$ & $20.12 \pm 0.55$ & $21.28 \pm 0.54$ & 5.3 \\
$B 2 M$ & $27.36 \pm 0.57$ & $26.26 \pm 0.64$ & $29.43 \pm 1.8$ & 7.0 \\
\hline
\end{tabular}


A
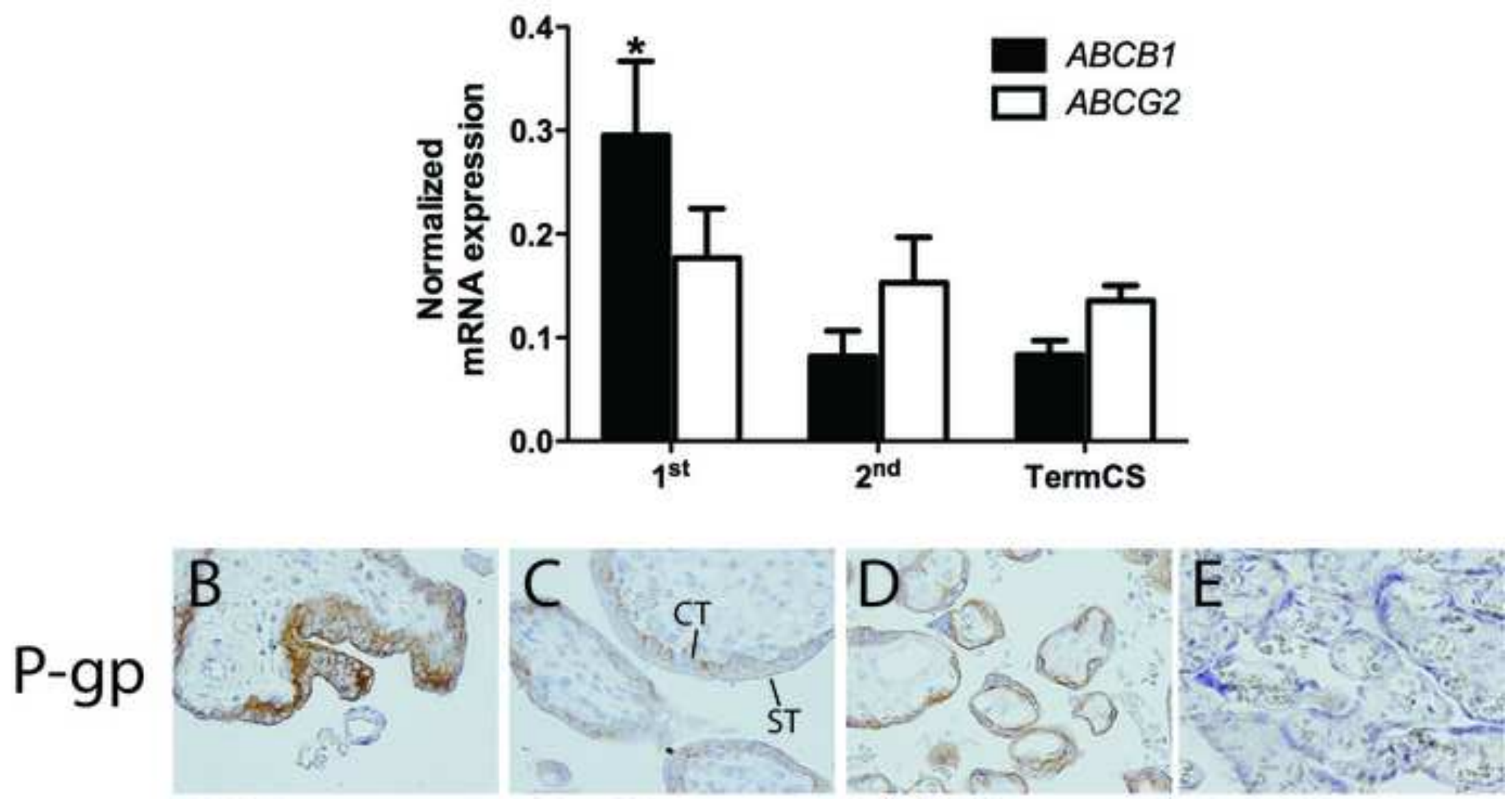

BCRP
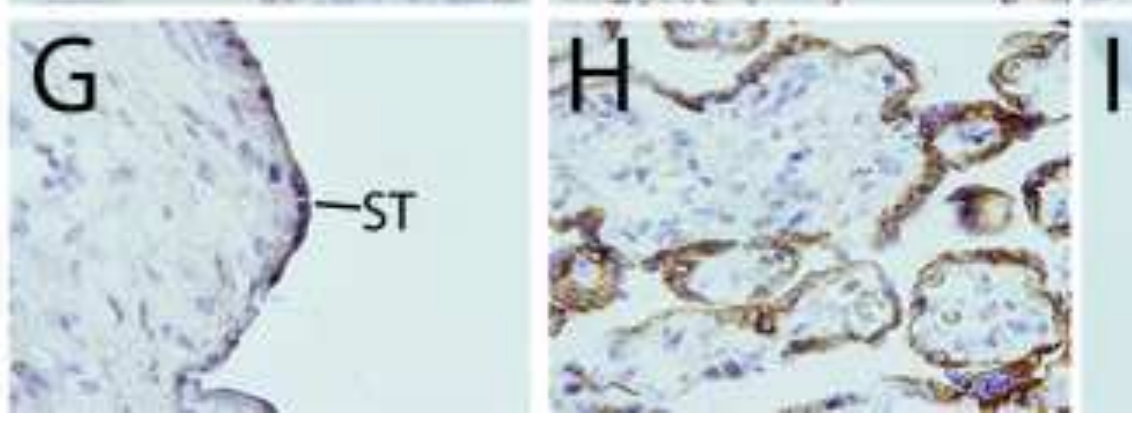
Figure 2

Click here to download high resolution image

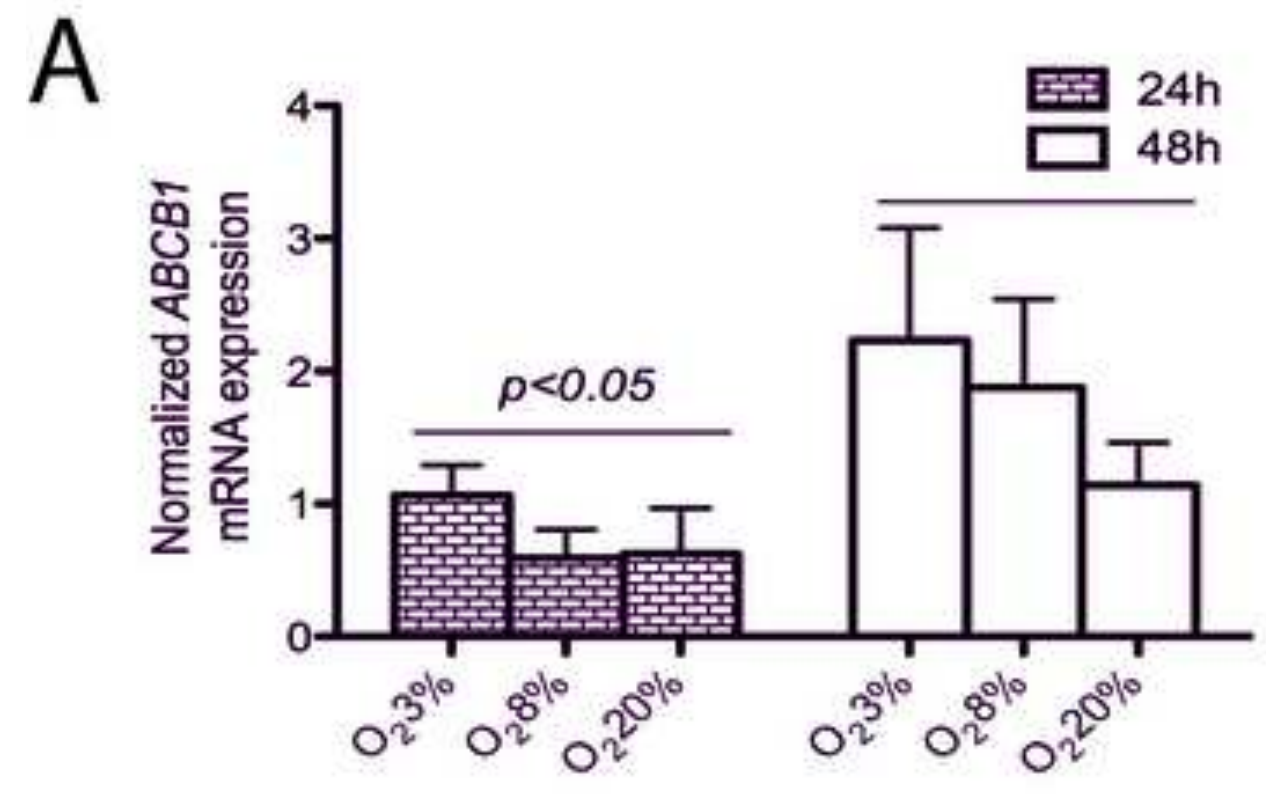

B

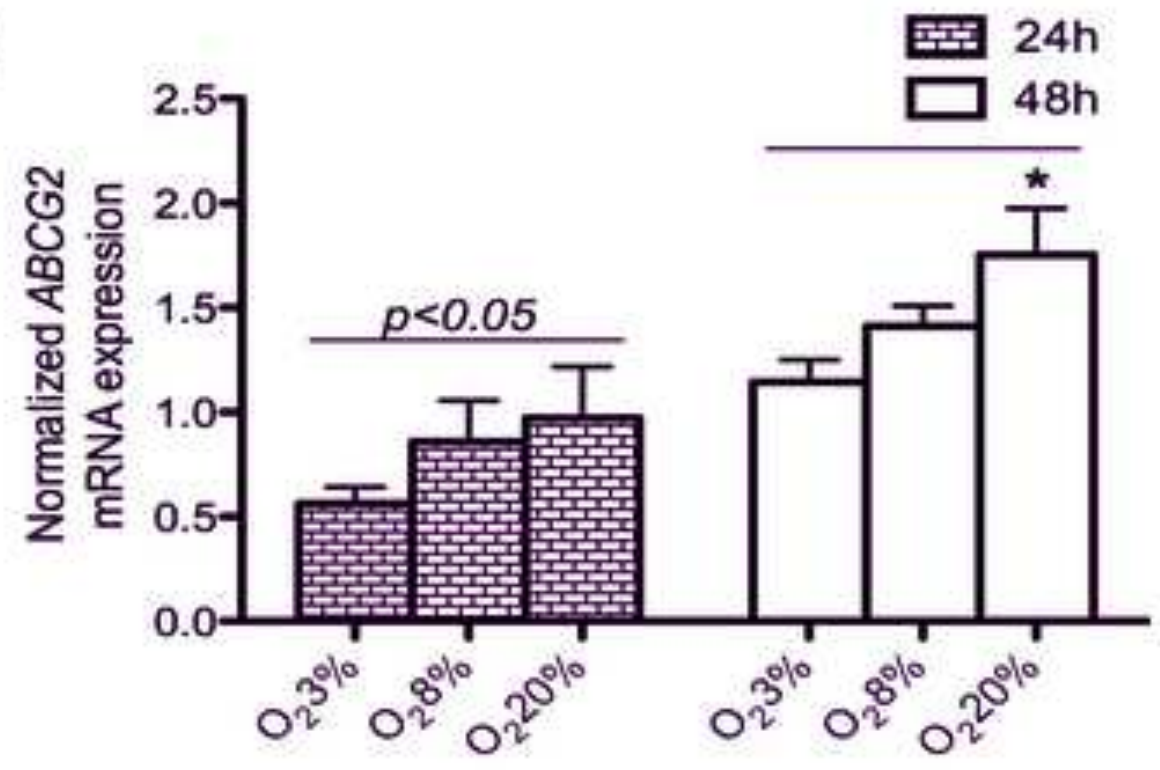

C

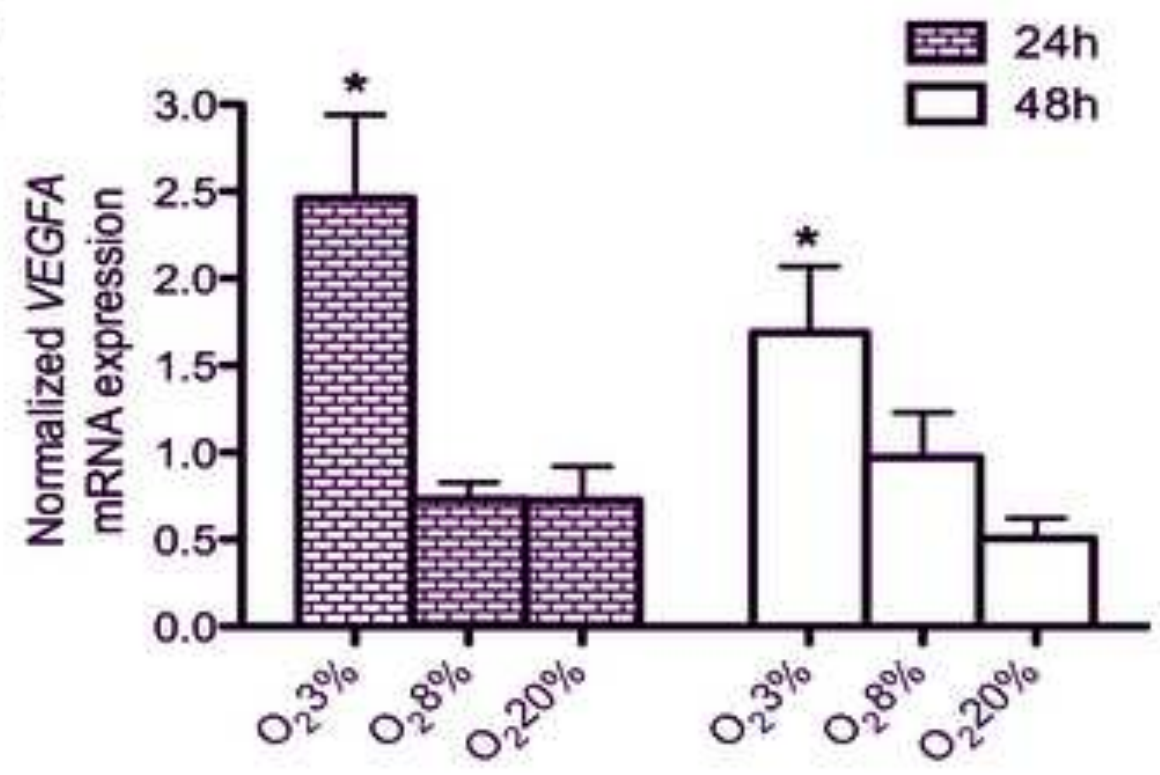



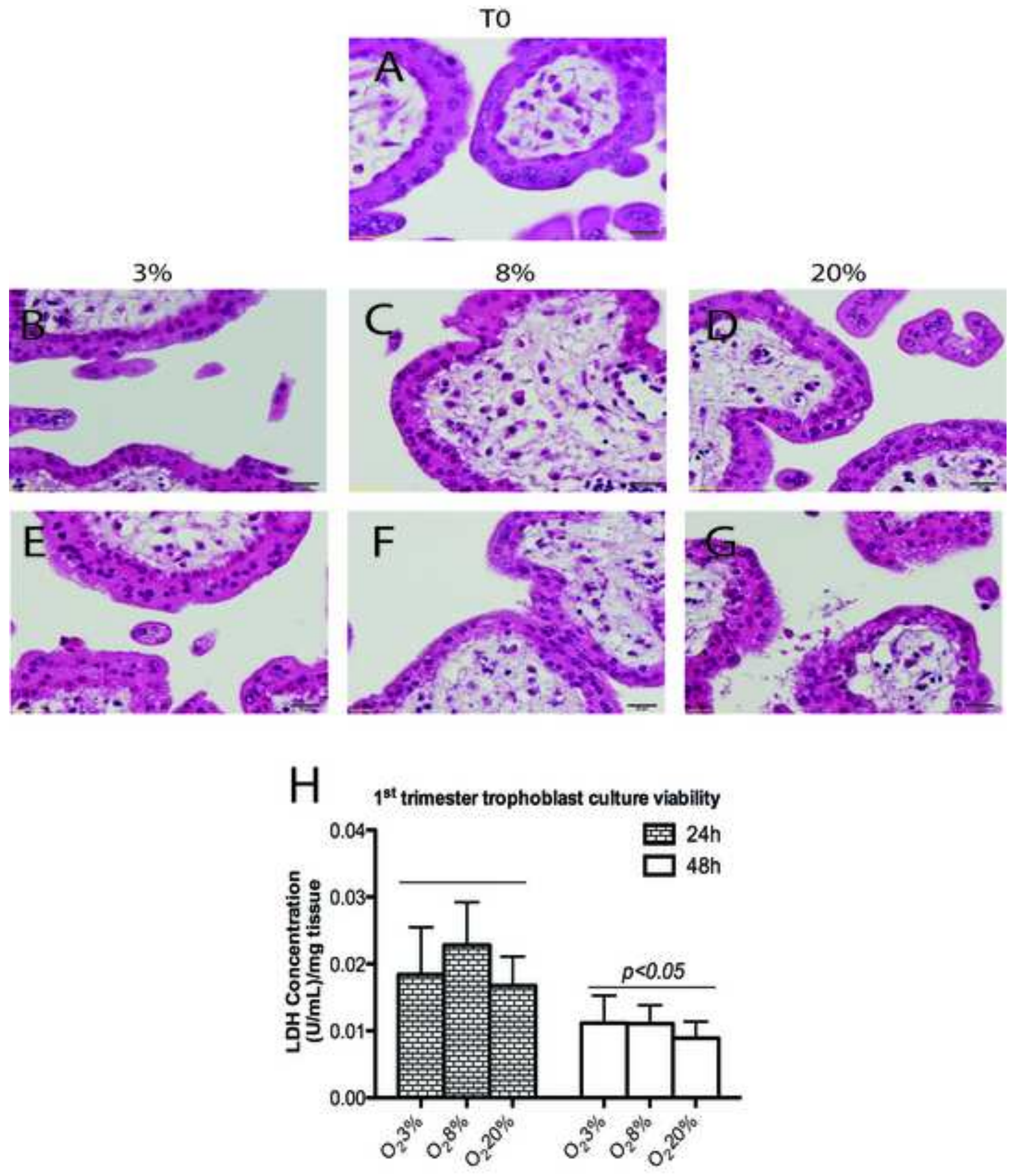

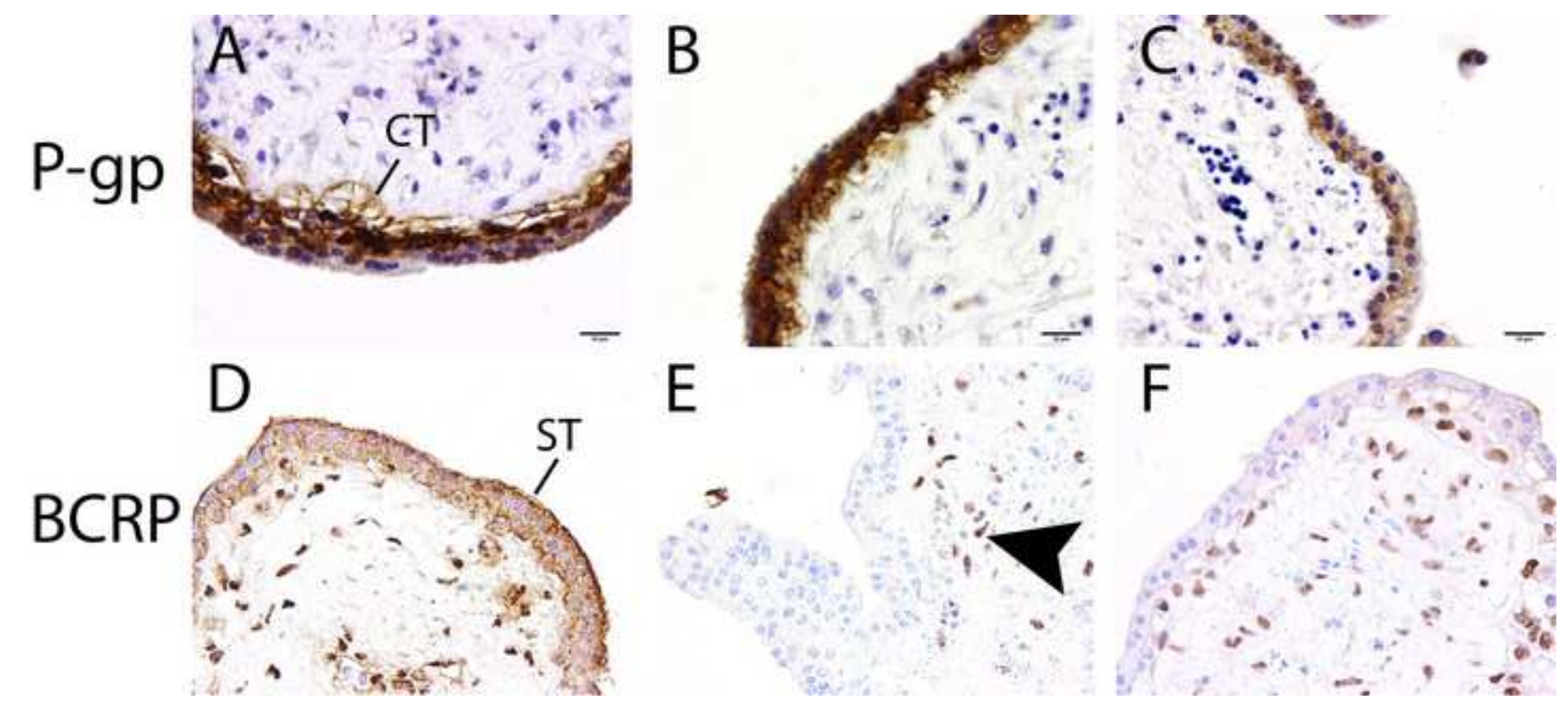